\title{
Expanding the Applications of Picosecond Lasers
}

\author{
Rawaa Almukhtar ${ }^{1 *}$, Joshua Ortego ${ }^{1}$, Brain Lee ${ }^{1}$ and Deirdre Hooper ${ }^{1,2}$ \\ ${ }^{1}$ Department of Dermatology, LSU Health Sciences Center, United States \\ ${ }^{2}$ Department of Dermatology, Tulane University, United States
}

Submission: July 04, 2018; Published: July 24, 2018

*Corresponding author: Rawaa Almukhtar, Department of Dermatology, LSU Health Sciences Center, United States, Email: ralmuk@lsuhsc.edu

\begin{abstract}
Picosecond laser technology has garnered much interest since arriving on the dermatological scene. While its effectiveness in removing tattoos has been well documented, demonstrating its use in other skin lesions is an ongoing process. Because quality switched nanosecond lasers and picosecond lasers share a similar mechanism, clinicians hope that picosecond lasers will prove to be useful for similar skin lesions. There has been a great focus in particular on proving its effectiveness in treating pigmented lesions, acne scarring, photodamage, and wrinkling. The early data and impressive safety profile of picosecond lasers suggest that clinicians may have another tool they can use to treat these troublesome skin conditions particularly in patients with darker skin types.
\end{abstract}

Keywords: Picosecond; Laser; Hyperpigmentation; Acne; Scarring; Photodamage; Wrinkles

Abbreviations: QS: Quality Switched; DLA: Diffractive Lens Array; CALM: Café-au-lait Macule; Nd: YAG: Neodymium-doped Yttrium Aluminum Garnet; HQ: Hydroquinone; VEN: Verrucous Epidermal Nevi; PIH: Post-Inflammatory Hyperpigmentation

\section{Introduction}

Ever since lasers were invented in the 1960s, dermatologists were among the first physicians who attempted to identify possible applications in diseases [1]. This began a long tradition of clinicians eagerly researching the various applications of each new breakthrough in laser technology. Picosecond laser technology first showed promise in the field of dermatology for its effectiveness in the removal of tattoo pigment. Given its similarity to quality switched (QS) nanosecond lasers, it has been hypothesized that picosecond technology may be effective for treating many of the same lesions that show a response to QS nanosecond lasers. By shortening the pulse duration to the order of picoseconds, the thermal stress time of tissue can be avoided as well as the thermal damage and pigmentary alterations associated with it. Longer wavelengths correspond with deeper penetrance into dermal layers. Higher fluences correspond with increased vacuole formation necessary to stimulate release of factors that lead to dermal remodeling. It has been demonstrated that tissue with a higher melanin index correlates with an increase in intra-epidermal vacuole production and less unintended vascular injury due to absorption by hemoglobin. This implies that darker skin types are more likely to confine injury to the epidermis and spare the vasculature [2]. This has been shown to be of particular importance for the treatment of patients with Fitzpatrick type IV to VI skin [3]. In these patients, dyspigmentation is a common side effect of nanosecond laser treatment due to microscopic thermal damage that follows melanosomal destruction. Increased dermal collagen and elastin following picosecond laser treatments has also been demonstrated [2]. This is likely due to the release of chemokines, cytokines, and various growth factors by keratinocytes in response to tissue injury [4]. This implies that picosecond lasers may be effective for cosmetically improving disfiguring scars and wrinkles. Alexandrite and neodymium-doped yttrium aluminum garnet (Nd:YAG) are the two crystal mediums used for solidstate lasers. The $755 \mathrm{~nm}$ picosecond alexandrite laser (PicoSure, Cynosure, Westford, MA) with diffractive lens array (DLA) and the dual wavelength 1,064/532 nm fractionated picosecond Nd:YAG laser (PicoWay Resolve, Synderon Candela, Irvine, CA) are the most commonly used laser types. Identifying optimal wavelengths and laser settings for particular lesion types can be challenging and clinicians are often guided by professional judgement.

\section{Effectiveness for Pigmented Lesions}

Treatment of pigmented lesions with picosecond laser technology has been shown to be an effective and safe method for restoring natural skin tone and decreasing hyperpigmentation using both subjective and objective measures. There are a wide variety of pigmented skin lesions that have been treated with 
picosecond lasers. While these early studies are limited by patient numbers, the results have been promising and the safety profile is maintained in all skin types.

Café-au-lait macules (CALMs) are very prevalent pigmented lesions that have proven to be quite difficult to treat with laser therapy. Inconsistent results have given clinicians a poor idea of which treatment modalities are most effective. While considered to be effective, the QS Nd: YAG 1064nm laser demonstrated near complete to complete clearance in only one third of cases and approximately one fourth of lesions recurred at 4 months on average [5]. Picosecond laser treatments for these lesions may be superior to the recommended QS Nd: YAG 1064nm laser [6]. In a series of 16 patients treated with a picosecond $532 \mathrm{~nm} \mathrm{Nd:}$ YAG laser, 15 patients had pigmentation clearance ranging from good to excellent with nine of these patients reporting nearcomplete to complete clearance, and only one patient with no response to treatment at all. Two patients in this series reported partial recurrence [6]. Patients typically require 2 to 4 sessions for adequate treatment response and recurrence of lesions was very rare [6-9].

QS lasers have been shown to be an effective modality for the treatment of nevus of Ota with a majority of patients experiencing greater than $75 \%$ clearance after an average of 5.5 treatment sessions [8-10]. Patients treated with a $755 \mathrm{~nm}$ alexandrite picosecond laser required an average of 3.5 sessions to achieve a comparable clinical satisfaction [8]. In one case series, 3 patients with nevus of Ota who had either stopped responding or had lesions resistant to QS laser treatment were treated with a $755 \mathrm{~nm}$ alexandrite picosecond laser. All patients demonstrated significant cosmetic improvement and were well pleased with their response [11]. Studies demonstrating the use of picosecond lasers in the treatment of nevus of Ota are sparse and limited by small patient numbers, yet the data suggest it is highly effective.

Treatment of melasma is centered on reducing the severity of hyperpigmentation to improve quality of life and limit recurrence after successful treatment. Topical agents such as hydroquinone (HQ) and azelaic acid are the current first-line treatment [12]. QS lasers and ultrapulsed CO2 lasers are not recommended first line agents in patients with melasma due to thermal damage and risk of dyspigmentation [13]. Nonablative fractionated resurfacing lasers have shown effectiveness yet recurrence occurs within 3 to 6 months after treatment in all cases [12]. Evidence for treatment of melasma with a $755 \mathrm{~nm}$ picosecond alexandrite laser was first documented in a case report of two Korean women who had previously reached a plateau in response to low-fluence QS laser therapy. These patients exhibited modest but significant clearing after 6 and 14 bimonthly treatment sessions [14]. A split-face trial was conducted comparing a fractional picosecond 1064 nm laser with 4\% HQ versus 4\% HQ alone. In 30 patients the mean melasma severity index was significantly decreased in the laser treated side though patient satisfaction and quality of life were similar [15]. Another split-face trial was conducted with
40 patients comparing a dual-wavelength (1064 and 595nm) picosecond laser in combination with topical $2 \%$ hydroquinone versus topical hydroquinone alone. It was found that weekly laser treatments with hydroquinone achieved significantly better clearance at 7 weeks compared to hydroquinone alone. Recurrence of melasma at the 12 -week evaluation did occur in $77 \%$ and $69 \%$ of patients treated with combination therapy and hydroquinone respectively [16]. Melasma has proven to be a very difficult lesion to treat with many patients often experiencing resistance to treatments and recurrence after successful treatment. Current data suggest that picosecond lasers may not be an improvement over the standard of care in melasma treatments.

Smaller studies have demonstrated the effectiveness of picosecond lasers in the treatment of other hyperpigmented skin lesions including verrucous epidermal nevi (VEN), Hori's nevus, solar lentigines, and even infraorbital dark circles. VEN was successfully treated with a picosecond $532 \mathrm{~nm} \mathrm{Nd:YAG} \mathrm{laser}$ after up to 6 treatment sessions. The average patient had a rated improvement of 3.7 in a 4-point scale and recurrence was not seen in any patients after a 12 month follow up [17]. 10 patients with infraorbital dark circles treated with a picosecond $755 \mathrm{~nm}$ alexandrite laser improved significantly after 3 treatment sessions and clearance was sustained at a 132 day follow up [18]. This same study did however find that patients receiving a single treatment with dual wavelength 532 and $1064 \mathrm{~nm}$ picosecond laser did not demonstrate any significant improvement. Solar lentigines are known to be susceptible to treatment with QS lasers but post-inflammatory dyspigmentation is a concerning side effect especially in patients with darker skin types [1921]. Out of 43 solar lentigines treated with a dual-wavelength $532 \mathrm{~nm}$ and $1064 \mathrm{~nm} \mathrm{Nd}$ YAG picosecond laser, the average improvement was 4.77 on a 5 point scale and post-inflammatory hyperpigmentation (PIH) only occurred in $4.65 \%$ of lesions [22]. For the treatment of Hori's nevus, a $755 \mathrm{~nm}$ picosecond alexandrite laser demonstrated superior efficacy to the QS alexandrite laser with a better side effect profile and a decreased incidence of PIH [23].

\section{Effectiveness in Acne Scarring}

Due to the successful treatment of acne scarring with QS nanosecond lasers, clinicians hoped picosecond lasers would display a similar effectiveness with a better side effect profile [24]. Clinical evidence on the efficacy for the treatment of rolling and boxcar-type acne scars has been promising in the few studies performed. Patients receiving 6 treatments with $755 \mathrm{~nm}$ picosecond alexandrite laser with DLA demonstrated significant improvement in scarring at 1 and 3 months follow ups. Histopathological examination at 3 months follow up revealed an increase in dermal collagen III, elastic fiber density, and mucin deposition in all layers [25]. A later study demonstrated that treatment with a higher number of pulses from this same laser had no statistical benefit compared to a standard number of pulses in the treatment of acne scarring and wrinkling [26]. 
A head to head study comparing treatment response to 1,064 and $532 \mathrm{~nm}$ wavelengths demonstrated improvement in acne scarring with no observable difference between the wavelengths [27]. While head to head trials have not yet been conducted between treatment modalities, picosecond lasers may be a safe alternative to skin types prone to pigment alterations and those nonresponsive to other therapies.

\section{Effectiveness in Wrinkles and Photodamage}

Photodamage and wrinkling have been shown to be responsive to QS lasers [26,28,29]. Picosecond laser treatment causes increased dermal collagen and elastin and therefore should be effective for treating sun damage and wrinkling [25]. A small study investigating the efficacy for treating photodamaged décolletage showed that treatment with the $755 \mathrm{~nm}$ picosecond alexandrite laser produced modest yet significant improvement with a very favorable safety profile [29]. These results were backed up by another study that showed very high patient satisfaction rates for those receiving laser treatments for skin rejuvenation on the dorsal hand and décolletage [30]. For the treatment of wrinkles, the $755 \mathrm{~nm}$ picosecond alexandrite laser has been found to be incredibly effective. Weiss et al showed that patients with a mean Fitzpatrick wrinkle score of 5.48 improved to 3.47 on 6 month follow up after receiving 4 full-face monthly treatments [28]. Biopsy results of specimens taken at 6 months follow up showed significant increases in dermal collagen and elastin fibers which correlated with improved appearance of photodamage, wrinkles, and texture. Compressing this treatment protocol to 2-3-week intervals resulted in expedited results with no appreciable increase in side effects [31]. A split-face study was conducted to better visualize the treatment effects of a $755 \mathrm{~nm}$ picosecond alexandrite laser when compared to a control side receiving no intervention. These patients experienced significant improvement in wrinkles and photoaging as well as improvement in dyspigmentation limited to the treated side [32].

\section{Safety}

The safety of picosecond lasers has been well documented. Occasionally patients requested topical anesthesia before undergoing treatments, but generally treatments are only mildly painful and well tolerated. The most common side effects across all studies is transient erythema and edema. Clinicians often regarded erythema as an end-treatment goal. A few studies have described self-limited blistering and desquamation following treatments with most cases resolving at one month follow up $[6,15]$. Significant blistering was a desired end-treatment effect in the treatment of verrucous epidermal nevi [33]. Crusting and scabbing have also been described with one study documenting a mean duration of 6.72 days [7,9,23,31]. A transient urticarial reaction was noted immediately after treatment that resolved acutely [29]. Interestingly, acneiform miliaras was observed on both sides of the face in one patient of a split-face picosecond alexandrite laser vs nanosecond alexandrite laser; it resolved after 10 days [23]. PIH though rare was the most persistent documented side effect of laser treatment. PIH was found to last approximately 40 days in one study and all studies demonstrated resolution of PIH at last follow up $[3,18,23]$. The transient nature of $\mathrm{PIH}$ following picosecond laser treatments is especially important in the management of patients with darker skin types as other laser modalities are infrequently used in these patients.

\section{Conclusion}

The use of picosecond lasers in pigmentary lesions has been characterized based on lesion type and extent with a keen awareness of side effects particularly in darker skin types. Histological examination of skin treated with picosecond lasers revealed a marked increase in collagen and elastin fibers which correlates with its effect in treating rhytides and photodamaged skin. Though caused by a different underlying mechanism, acne scarring has also been demonstrated to be responsive to picosecond laser therapy. Identification of optimal laser settings for specific lesion types has not yet been studied. Number of treatment sessions and intervals between treatments are often left to clinical judgement. The few studies examining shortened interval times and higher pulse treatments have shown comparable efficacy and safety to standard treatment regimens. Moderate erythema was often a desired end-treatment effect and number of passes and pulse count were based on the amount needed to achieve this effect. While many of these studies are limited by small patient numbers, the results have been very promising. Patients tend to be well satisfied with their improvement whether the outcome is evened skin tone or improvement in texture.

\section{References}

1. Geiges ML (2011) History of lasers in dermatology. Curr Probl Dermatol 42: 1-6.

2. Tanghetti EA (2016) The histology of skin treated with a picosecond alexandrite laser and a fractional lens array. Lasers Surg Med 48(7): 646-652.

3. Haimovic A, Brauer JA, Cindy Bae YS, Geronemus RG (2016) Safety of a picosecond laser with diffractive lens array (DLA) in the treatment of Fitzpatrick skin types IV to VI: A retrospective review. J Am Acad Dermatol 74(5): 931-936.

4. Werner S, Krieg T, Smola H (2007) Keratinocyte-fibroblast interactions in wound healing. J Invest Dermatol 127(5): 998-1008.

5. Kim HR, Ha JM, Park MS, Lee Y, Seo YJ, et al. (2015) A low-fluence 1064nm Q-switched neodymium-doped yttrium aluminium garnet laser for the treatment of cafe-au-lait macules. J Am Acad Dermatol 73(3): 477483.

6. Artzi O, Mehrabi JN, Koren A, Niv R, Lapidoth M, et al. (2018) Picosecond $532 \mathrm{~nm}$ neodymium-doped yttrium aluminium garnet laser-a novel and promising modality for the treatment of cafe-au-lait macules. Lasers Med Sci 33(4): 693-697.

7. Belkin DA, Neckman JP, Jeon H, Friedman P, Geronemus RG, et al. (2017) Response to Laser Treatment of Cafe au Lait Macules Based on Morphologic Features. JAMA Dermatol 153(11): 1158-1161.

8. Chan JC, Shek SY, Kono T, Yeung CK, Chan HH, etal. (2016) A retrospective analysis on the management of pigmented lesions using a picosecond 755nm alexandrite laser in Asians. Lasers Surg Med 48(1): 23-29. 
9. Levin MK, Ng E, Bae YS, Brauer JA, Geronemus RG (2016) Treatment of pigmentary disorders in patients with skin of color with a novel $755 \mathrm{~nm}$ picosecond, Q-switched ruby, and Q-switched Nd:YAG nanosecond lasers: A retrospective photographic review. Lasers Surg Med 48(2): 181-187.

10. Kono T, Nozaki M, Chan HH, Mikashima Y (2001) A retrospective study looking at the long-term complications of Q-switched ruby laser in the treatment of nevus of Ota. Lasers Surg Med 29(2): 156-159.

11. Chesnut C, Diehl J, Lask G (2015) Treatment of nevus of ota with a picosecond 755-nm alexandrite laser. Dermatol Surg 41(4): 508-510.

12. Trivedi MK, Yang FC, Cho BK (2017) A review of laser and light therapy in melasma. Int J Womens Dermatol 3(1): 11-20.

13. Angsuwarangsee S, Polnikorn N (2003) Combined ultrapulse CO2 laser and Q-switched alexandrite laser compared with Q-switched alexandrite laser alone for refractory melasma: split-face design. Dermatol Surg 29(1): 59-64.

14. Lee YJ, Shin HJ, Noh TK, Choi KH, Chang SE (2017) Treatment of Melasma and Post-Inflammatory Hyperpigmentation by a Picosecond 755-nm Alexandrite Laser in Asian Patients. Ann Dermatol 29(6): 779781.

15. Chalermchai T, Rummaneethorn P (2018) Effects of a fractional picosecond $1,064 \mathrm{~nm}$ laser for the treatment of dermal and mixed type melasma. J Cosmet Laser Ther 20(3): 134-139.

16. Choi YJ, Nam JH, Kim JY, Min JH, Park KY, et al. (2017) Efficacy and safety of a novel picosecond laser using combination of 1064 and $595 \mathrm{~nm}$ on patients with melasma: A prospective, randomized, multicenter, splitface, $2 \%$ hydroquinone cream-controlled clinical trial. Lasers Surg Med 49(10): 899-907.

17. Negishi K, Akita H, Matsunaga Y (2018) Prospective study of removing solar lentigines in Asians using a novel dual-wavelength and dual-pulse width picosecond laser. Lasers Surg Med.

18. Vanaman Wilson MJ, Jones IT, Bolton J, Larsen L, Wu DC, et al. (2018) Prospective studies of the efficacy and safety of the picosecond 755 1,064, and $532 \mathrm{~nm}$ lasers for the treatment of infraorbital dark circles. Lasers Surg Med 50(1): 45-50.

19. Ho SG, Yeung CK, Chan NP, Shek SY, Chan HH (2011) A comparison of Q-switched and long-pulsed alexandrite laser for the treatment of freckles and lentigines in oriental patients. Lasers Surg Med 43(2): 108-113.

20. Vachiramon V, Panmanee $\mathrm{W}$, Techapichetvanich T, Chanprapaph $\mathrm{K}$ (2016) Comparison of Q-switched Nd: YAG laser and fractional carbon dioxide laser for the treatment of solar lentigines in Asians. Lasers Surg Med 48(4): 354-359.

21. Ho SG, Chan NP, Yeung CK, Shek SY, Kono T, et al. (2012) A retrospective analysis of the management of freckles and lentigines using four different pigment lasers on Asian skin. J Cosmet Laser Ther 14(2): 7480 .
22. Guss L, Goldman MP, Wu DC (2017) Picosecond 532nm NeodymiumDoped Yttrium Aluminium Garnet Laser for the Treatment of Solar Lentigines in Darker Skin Types: Safety and Efficacy. Dermatol Surg 43(3): 456-459.

23. Yu W, Zhu J, Yu W, Lyu D, Lin X, et al. (2017) A split-face, single-blinded, randomized controlled comparison of alexandrite $755 \mathrm{~nm}$ picosecond laser versus alexandrite $755 \mathrm{~nm}$ nanosecond laser in the treatment of acquired bilateral nevus of Ota-like macules. J Am Acad Dermatol. pii: S0190-9622(17)32893-1.

24. Connolly D, Schilling L, Saedi N (2017) Advances in fractional technology for skin rejuvenation, skin tightening, drug delivery, and treating scars and skin defects. Semin Cutan Med Surg 36(4): 138-147.

25. Brauer JA, Kazlouskaya V, Alabdulrazzaq H, Bae YS, Bernstein LJ, et al. (2015) Use of a picosecond pulse duration laser with specialized optic for treatment of facial acne scarring. JAMA Dermatol 151(3): 278-284.

26. Dierickx C (2018) Using normal and high pulse coverage with picosecond laser treatment of wrinkles and acne scarring: Long term clinical observations. Lasers Surg Med 50(1): 51-55.

27. Bernstein EF, Schomacker KT, Basilavecchio LD, Plugis JM, Bhawalkar JD (2017) Treatment of acne scarring with a novel fractionated, dual-wavelength, picosecond-domain laser incorporating a novel holographic beam-splitter. Lasers Surg Med 49(9): 796-802.

28. Weiss RA, McDaniel DH, Weiss MA, Mahoney AM, Beasley KL, et al. (2017) Safety and efficacy of a novel diffractive lens array using a picosecond $755 \mathrm{~nm}$ alexandrite laser for treatment of wrinkles. Lasers Surg Med 49(1): 40-44.

29. Wu DC, Fletcher L, Guiha I, Goldman MP (2016) Evaluation of the safety and efficacy of the picosecond alexandrite laser with specialized lens array for treatment of the photoaging decolletage. Lasers Surg Med 48(2): 188-192.

30. Saluja R (2016) Evaluation of the Safety and Efficacy of a Low Fluence, Picopulsed, Alexandrite Laser in a Pico-Toning Technique With a Diffractive Lens Optic for the Treatment of Photodamage and Textural Improvement in "Off the Face" Applications. J Drugs Dermatol. 15(11): 1398-1401.

31. Khetarpal S, Desai S, Kruter L, Prather H, Petrell K, et al. (2016) Picosecond laser with specialized optic for facial rejuvenation using a compressed treatment interval. Lasers Surg Med 48(8): 723-726.

32. Ge Y, Guo L, Wu Q, Zhang M, Zeng R, et al. (2016) A Prospective SplitFace Study of the Picosecond Alexandrite Laser with Specialized Lens Array for Facial Photoaging in Chinese. J Drugs Dermatol 15(11): 13901396.

33. Levi A, Amitai DB, Mimouni D, Leshem YA, Arzi O, et al. (2018) Picosecond 532nm neodymium-doped yttrium aluminum garnet laser-a promising modality for the management of verrucous epidermal nevi. Lasers Med Sci 33(3): 597-601.
This work is licensed under Creative

Commons Attribution 4.0 License DOI: 10.19080/JOJDC.2018.01.555557
Your next submission with Juniper Publishers will reach you the below assets

- Quality Editorial service

- Swift Peer Review

- Reprints availability

- E-prints Service

- Manuscript Podcast for convenient understanding

- Global attainment for your research

- Manuscript accessibility in different formats

( Pdf, E-pub, Full Text, Audio)

- Unceasing customer service

Track the below URL for one-step submission https://juniperpublishers.com/online-submission.php 